\title{
A centralidade da declaração das partes ${ }^{1}$
}

\author{
The centrality of the parties' declaration
}

Resumo: A nova sistemática do CIC 1983 sobre a declaração das partes; a supremacia das declarações das partes; a diversificação e a classificação dos conceitos do CIC; rumo a um "discurso comum razoável"; os aspectos do correto exercício do contraditório em matéria probatória; a fase preparatória e a pastoral judiciária; a qualidade específica do

\section{Manuel Jesús Arroba Conde ${ }^{2}$}

1 Terceira conferência proferida no II ${ }^{\circ}$ Simpósio Canônico "Questões seletas de Direito Matrimonial e Penal Canônico", promovido pelo Instituto Superior de Direito Canônico Santa Catarina em 8-9 de maio de 2018.

2 Doutor, Professor e Presidente do Institutum Utriusque Iuris da Pontificia Universidade Lateranense de Roma. Recentes publicações do autor sobre o tema da conferência: com C. IZZI, Pastorale giudiziaria e prassi processuale nelle cause di nullità del matrimonio dopo la riforma operata con il Motu proprio Mitis Iudex Dominus Iesus, Cinisello Balsamo 2017, 320 pp; Sviluppo in tema di protezione processuale dei diritti, in Il Diritto Ecclesiastico 1-2 (2017), pp. 25-42; O motu proprio Mitis Iudex en relaçâo ao conceito de processo justo, in Forum canonicum 12/1 (2017), pp. 5-26; La interpretación de las normas del MIDI sobre la apelación y la ejecutividad de las sentencias, in L. Ruano Espina- A. M. López Medina, Antropología cristiana y derechos fundamentales. Algunos desafios del siglo XXI al derecho canónico y eclesiástico del Estado, Madrid 2018, pp. 349-377. Anche nella rivista Estudios Eclesiásticos 93/367 (2018), pp. 745771; La Norma Missionis en la reforma procesal, in Vergentis 6 (2018) pp. 2138; anche in Aa.Vv., El proceso de declaración de nulidad del vínculo matrimonial canónico, San Isidro 2018, pp. 78-112; Le dichiarazioni delle parti come valorizzazione della dimensione personalista del processo matrimoniale canonico, in Apollinaris LXXX (2007), pp. 687-712. Anche in P. Gherri (ed.), Diritto canonico. Antropologia e personalismo. Atti della seconda giornata canonistica interdisciplinare, Roma 2008, pp. 139-162. 
interrogatório das partes; a publicação antecipada das provas.

Palavras-chave: Direito Processual. Declaração das partes. Processo mais breve. Pastoral judiciária. care; the specific quality of the interrogation of the parties; the early publication of proofs.

Keywords: Procedural Law. Declaration by the parties. Briefer process. Judicial pastoral.

\section{Introdução}

Referir-se à centralidade da declaração das partes significa, da minha parte, tentar expressar a profunda convicção de que seja necessário focalizar o direito probatório canônico a partir da lei e, acima de tudo, da lógica e da razão, que obrigam a reconhecer um lugar central às declarações das partes num processo como o processo canônico de nulidade matrimonial.

\section{A nova sistemática do CIC 1983 sobre a declaração das partes}

Em relação ao código anterior, são bem conhecidas as três novidades da disciplina atual sobre este meio de prova. A primeira novidade foi atribuir valor probatório a todas as declarações das partes, e não apenas à confissão contra si mesmo, superando também a rígida concepção do Art. 117 da Provida Mater, que estabeleceu a inutilidade das declarações das partes para provar a nulidade. Interessa-nos mais determo-nos na segunda novidade: as declarações das partes, na relação das provas típicas, foram colocadas em primeiro lugar, o que, no meu entender, tem importantes repercussões em todo o sistema probatório. Não há dúvida de que, aparentemente, a novidade mais marcante (a terceira) foi ter atribuído possível força probatória plena à declaração das partes quando não houver a confirmação direta em outras provas a respeito de certos aspectos que são determinantes para a definição da causa.

Passados 20 anos de sua entrada em vigor, é necessário reconhecer que, na prática, essas três novidades da normativa (seja como reflexo da nova sensibilidade, seja no que tem de materialmente novo), não foram adequadamente recebidas, nem na Rota e nem em muitos 
tribunais locais, com o risco de se desperdiçar a riqueza que esta nova lei contém.

Podemos fazer referência a duas posições extremas: a mais superficial, é a que compromete a natureza judicial do processo, pois atribui à parte o papel que é próprio do juiz, como se as partes fossem juízes em sua própria causa; a segunda posição, mais imutável, é a que deseja aplicar a nova lei de acordo com os parâmetros de uma hermenêutica antiga (uma situação que se reflete em certas sentenças e em parte da doutrina). Nenhuma das duas posições respeita a nova lei, porém são talvez causadas por ela mesma, razão pela qual o estudo de cada novidade deve vir acompanhado do esforço por compreender com esse novo horizonte os mesmos conceitos técnicos.

Apresento de forma muito sintética a primeira das novidades, isto é, o valor de prova que as declarações das partes possuem hoje, ou seja, a lei finalmente reconhece que as declarações das partes, independentemente do seu conteúdo, são um meio de comprovação dos fatos e, por isso, têm valor de prova.

Toda declaração das partes é hoje considerada como um instrumento de comprovação dos fatos e de busca da verdade, sem que tenha relevância se o seu conteúdo é favorável ou contrário à própria posição processual das partes.

\section{A supremacia das declarações das partes}

Do quanto contido nas atas do "coetus de processibus" da comissão que se ocupou dos trabalhos preparatórios da nova lei, é possível perceber que a colocação da declaração das partes no primeiro lugar da lista de provas do código atual não foi um mero detalhe formal e irrelevante. Nelas se adverte que as provas foram ordenadas de acordo com a sua importância. Esta novidade será incompreensível se não se levar em conta que os postulados conciliares encerram uma renovada sensibilidade sobre a dignidade da pessoa e dos fiéis e que a partir deles é que foram formulados os princípios de revisão do código. Entre eles, um se relaciona especialmente com o processo e com o nosso tema: a necessidade de encurtar as distâncias, sem confundi-las, entre o foro interno e o foro externo. Não há dúvida de que a melhor manei- 
ra de se evitar cisões entre as convicções de consciência dos fiéis (no foro interno) e as possibilidades de reconhecer seu valor jurídico no processo (no foro externo) era predispor uma adequada disciplina sobre as declarações na fase probatória.

É importante não esquecer, portanto, que a supremacia das declarações das partes no sistema de prova canônica obedece acima de tudo a essas razões metajurídicas, que não podem ser interpretadas em oposição à busca da verdade objetiva, como objetivo do processo. Este nobre objetivo, de fato, exige uma atitude humilde porque, assim como a verdade objetiva não pode ser alcançada com atitudes superficiais, que acabam atribuindo às partes o papel de juízes em sua própria causa, tão pouco a verdade não é alcançada com atitudes prepotentes, que não consideram a parcela da verdade que cada um dos protagonistas dos fatos possui. Na realidade, a supremacia das declarações das partes obedece também a razões estritamente jurídicas, a saber, a exigência de recorrer à fonte mais segura para comprovar os fatos e a razoável certeza moral que oferece o critério de convergência em relação aos fatos que têm uma clara projeção interpessoal.

A experiência pessoal de cada cônjuge, em se tratando de fatos de natureza íntima, é a fonte mais segura, como, aliás, o admitiu a jurisprudência imediatamente subsequente à Provida Mater, sem que o supracitado Artigo 117 representasse um obstáculo intransponível. Isso foi reconhecido sobretudo pelas normas particulares dadas para o Vicariato da Suécia em 1951, pois ao estabelecerem o valor da declaração de cada parte, recordam que "in hoc causaum genere... res est in interiore animo recondita". Por outro lado, a razoável certeza que oferece o critério da coincidência entre as partes, relativa aos fatos que têm uma projeção interpessoal, não pode ser considerada ausente nem sequer no código de 1917. Esta legislação reconhecia valor de prova à confissão "contra se". É sabido que confessar é admitir a verdade de um fato proposto pela outra parte, fazendo com que haja coincidência entre ambas, independentemente de que a essa coincidência seja outorgada valor de prova plena.

Tudo isso foi recebido e valorizado na disciplina do Código de 1983. No que se refere à idoneidade da declaração como fonte digna de investigação, o código estabelece a necessidade de se interrogar as 
partes, não só pela lógica exigência do exercício do direito de defesa, mas por causa da necessidade de "aptius eruendam veritatem" (c.1530). Quanto a convergência entre as partes, não deve passar despercebido que na norma geral a respeito dos fatos que constituem o objeto da prova (c. 1526, § 2), foram excluídos aqueles em que as partes coincidem, a menos que a sua investigação seja imposta pela lei ou pelo juiz. Nas causas matrimoniais, por pertencerem ao bem público, a lei exige a prova desses fatos e, portanto, ao se colocar o tema, eles não podem ficar de fora. Isso não significa que a coincidência observada nos resultados da prova seja irrelevante. O mesmo ocorre com a confissão judicial, que em causas de bem público não exime a outra parte do ônus de provar o fato confessado, sem diminuir a certeza razoável que deriva da confissão, seja pela coincidência indireta entre as partes, seja por causa da validade do critério psicológico segundo o qual é difícil mentir contra si mesmo.

\section{A diversificação e a classificação dos conceitos do CIC}

Esta última advertência nos faz entender a importância do uso de uma terminologia adequada, que permita distinguir com rigor técnico a diversidade de conceitos utilizados no Código com respeito às declarações das partes. Não se devem confundir conceitos que, devido à sua diversificada relevância probatória, requerem uma classificação adequada. A Dignitas Connubii, ultrapassando o papel dos instrumentos normativos - a tradição evita oferecer definições -, estabelece duas distinções no conceito de confissão. Eu não entendo as razões e penso que tudo isso pode dificultar a clareza.

Em qualquer caso, tanto por razões lógicas como pela superioridade que corresponde ao código, é necessário distinguir entre as declarações das partes que não fazem parte das provas (integradas nos "acta", mas não nos "probatas") e as que o são a pleno título. Entre as primeiras se incluem as afirmações que a parte pronuncia uma vez iniciado o processo (ou seja, no tempo suspeito) e fora do interrogatório (no libelo, na fase de fixação do "dubium", nas possíveis respostas escritas a partir de casa, subtraindo o interrogatório judicial). O interrogatório é o meio legítimo para compensar a inclinação natural de re- 
meter os fatos de acordo com a própria visão subjetiva das coisas, uma vez iniciada a causa. Por isso, não são excluídas do conceito de prova as declarações extrajudiciais da parte antes do processo (ou seja, em tempo não suspeito). Devem ser aplicadas a distinção entre declaração ou confissão, conforme sejam favoráveis ou contrárias à própria tese na causa, tanto às respostas oferecidas no interrogatório, quanto às afirmações extrajudiciais anteriores ao processo. Além disso, a distinção entre declaração e confissão, a meu juízo, não deve ser usada como uma classificação global das respostas e afirmações, mas deve ser aplicada a cada um dos fatos e detalhes da investigação.

Acredito que somente com a devida cautela e rigor é possível compreender o nível de comprovação que alcançou cada um dos referidos fatos históricos e, sobretudo, estabelecer o valor que tem cada um desses fatos em relação à comprovação do fato jurídico (thema probandum) objeto da causa. Em relação a isso, o Código sugere que se distinga entre aqueles fatos que obtém uma confirmação direta (c. 1572 , 4), os que resultam um indício (isto é, um fato intimamente relacionado ao fato principal que se investiga), os que são adminículos (circunstâncias relevantes do matrimônio, mesmo que elas não tenham relação direta com o objeto da prova) e os que são apenas elementos de credibilidade subjetiva (totalmente alheios ao tema em discussão, porém muito importantes para avaliar as provas oferecidas).

\section{Rumo a um "discurso comum razoável”}

O último conceito indicado, isto é, os "elementos de credibilidade subjetiva", nos permite dar um último passo em nossa reflexão sobre a posição central que a declaração das partes ocupa no conjunto das provas, colocando sobre a mesa um problema epistemológico muito sério, mas que deve ser abordado com confiança e otimismo antropológico. Considero a confiança na força comunicativa da razão a melhor garantia para enfrentar as dificuldades que envolvem a comprovação de fatos que, em sua projeção interpessoal, podem ser objeto de interpretações subjetivas não facilmente harmonizadas entre si. Está claro que a comprovação de fatos com relevância comum requer, por parte de seus protagonistas, suficiente abertura e disponibilidade ética 
para se submeter à crítica e corrigir as possíveis distorções subjetivas da própria versão das coisas.

Compreendo que tal apelo à lealdade processual possa ser compreendido (como já me opuseram outras vezes) como ingenuidade. Considero-me satisfeito caso se trate de ingenuidade evangélica, entendida apenas pelos simples, com um coração limpo de preconceitos arbitrários. Mas também aos simples é feito o convite para ser astuto como as serpentes. E o que quero dizer é que as garantias oferecidas por uma adequada relação comunicativa entre as partes, no período probatório, sem diminuir a importância de um comportamento ético adequado, têm menos a ver com sua sinceridade subjetiva do que com a habilidade de forçá-las a desenvolver um discurso processual comum razoável.

Neste sentido, devemos valorizar o quanto contido em uma só palavra, o advérbio "semper" do c. 1530. Que o juiz, a fim de descobrir melhor a verdade, possa ou deva sempre interrogar as partes (se uma parte o solicitar), significa algo mais do que a óbvia admissão dessas provas no processo. Interrogar sempre significa poder ou dever fazê-lo mais de uma vez e em qualquer momento, se o exigir a descoberta da verdade. A astúcia está nessa capacidade e não no uso de prejuízos infundados sobre a falsidade das partes, contrária à dignidade das pessoas. É preferível repetir o interrogatório das partes antes que multiplicar testemunhas, dificilmente informadas dos fatos determinantes, que são íntimos e interpessoais. Não só é preferível; é obrigatório fazê-lo se houver elementos de aparente contraposição, como é lógico que ocorra quando se trata de investigar fatos enraizados em uma dura experiência de fracasso interpessoal e que raramente são interpretados de maneira comum.

Essa dinâmica de confronto progressivo entre as partes, preferida pelo legislador, mesmo multiplicando possíveis diferenças na interpretação subjetiva dos fatos, permite estabelecer com maior precisão, como já advertimos, a existência dos fatos em si mesmos, com base numa razoável convergência, construída com a cooperação direta dos protagonistas, sem desconsiderar levianamente, como incoerência ou contradição interna, o que cada um pontualiza ou corrige à luz das afirmações do outro. É verdade que no direito tradicional, a retratação 
goza de credibilidade só quando ocorre "incontinenter". Mas pontualizar não é exatamente retratar, muito menos quando se trata de fatos que se prefere esquecer, ou dos quais se foi elaborando uma interpretação pessoal que necessita ser contrastada com objetividade.

A jurisprudência interpretou o anterior c. 1750 de forma dinâmica, admitindo o possível valor das retratações ou correções por razões de consciência, o que seria próximo do atual conceito de "elemento de credibilidade subjetiva", com capacidade de corroborar até mesmo aqueles fatos sobre os quais apenas a parte havia oferecido prova direta (cc. 1536 e 1679).

A doutrina oferece várias interpretações convergentes sobre o significado deste conceito concreto, entendendo como elemento de corroboração os motivos pelos quais se instaura a causa, a atitude mantida no processo e, sobretudo, o estudo da personalidade das partes, pois pode ajudar a avaliar a objetividade de suas declarações e interpretações.

As normas para o Vicariato da Suécia impunham avaliar a experiência de conversão, frequentemente citada como a razão do processo, sem qualquer receio de que a evidente diferença entre a sinceridade subjetiva da conversão, como chave com a qual o convertido interpreta seu passado, e a objetividade dos fatos que declara, coloque em perigo a descoberta da verdade. A pessoa é a mesma. Assumir seu ponto de vista atual, como interpretação da consciência de um passado doloroso não é suficiente, mas é imprescindível, de modo que seria míope reduzir o interrogatório aos fatos passados, quase desinteressando-se das convicções atuais que explicam as aspirações e posições no processo.

A importância da interpretação pessoal das partes obriga, na produção da prova, a oferecer-lhes a oportunidade, antes de emanar o decreto de conclusão da causa, de esclarecer possíveis divergências com os resultados obtidos com as outras provas, se é que se trata de verdadeiras contradições e não, como muitas vezes acontece, de simples desconhecimento, por parte de terceiros, dos fatos mais íntimos sobre os quais se investiga. As possíveis diferenças entre as versões das partes não são resolvidas com uma opção arbitrária, nem baseadas na mera prevalência numérica das provas, de modo que nenhum es- 
forço pode ser poupado na construção de um discurso comum razoável. Somente uma instrução dinâmica, a partir da igualdade de oportunidades, pode garantir esse discurso compartilhado, confiando na capacidade das partes de reconhecer reciprocamente seus argumentos.

\section{Os aspectos do correto exercício do contraditório em matéria probatória}

Naturalmente, construir um discurso comum entre as partes, impedindo que o contraditório degenere em um desencontro irracional de versões, requer uma série de medidas adequadas que, embora não contradigam a lei, talvez sejam protegidas de forma muito frágil no texto legal. Entramos assim na última parte de nossa reflexão, na qual gostaria de propor três questões relacionadas ao exercício correto do contraditório em relação às provas.

\subsection{A fase preparatória e a pastoral judicial}

A primeira questão se relaciona com a preparação da causa, que a título pleno deve ser considerada uma ação de pastoral judicial. A disponibilidade das partes para empreender uma comunicação como a exigida pelo processo, após uma experiência de fracasso afetivo tão radical, necessita de muita preparação. Não deixo de elogiar a insistência da Dignitas Connubii em obter a participação de ambos os cônjuges no processo, responsabilizando disso o juiz. Cabe a ele exortálos a abandonar atitudes de rancor e lhe são concedidas determinadas faculdades para reprimir comportamentos processuais dilatórios. Merece o mesmo elogio, após ter superado algumas incertezas anteriores, o reconhecimento da possibilidade de se apresentar conjuntamente o libelo.Tudo isso aperfeiçoa as normas do código e é um passo à frente na exigência de construir o discurso comum.

No entanto, são poucas e nem sempre acertadas as normas sobre a fase prévia do processo. Proibir os servidores do tribunal de intervir nas causas em que ofereceram orientações é teoricamente lógico, mas muito longe da situação real das Igrejas locais. É preciso ser criativo e comprometer-se mais com a preparação de pessoas que en- 
tendam bem o significado do processo. Creio que nesta linha teremos de escolher, com os requisitos adequados, o grupo de advogados admitidos em cada tribunal, que têm, dentre os seus deveres deontológicos (dado que existe uma deontologia forense especificamente canônica), a incumbência de oferecer a devida informação sobre o sentido do processo a seu assistido, e inclusive para a outra parte. A práxis da mediação familiar, que surge como alternativa à justiça regulada, nos casos de separação e divórcio, oferece sugestões interessantes para esse momento delicado, anterior à introdução da causa.

\subsection{A qualidade especifica do interrogatório das partes}

Em segundo lugar, creio que o interrogatório das partes deve ser enfrentado com critérios de qualidade específicos, respeitando os dados normativos que lhe dão supremacia, portanto com medidas que nem sempre são utilizadas no interrogatório de testemunhas. Tanto às partes como às testemunhas deve-se permitir que se expressem com liberdade e deve-se registrar com fidelidade suas respostas. Mas é claro que essa exigência é ainda mais necessária nas declarações das partes, onde não é possível anular qualquer detalhe ou anotar suas respostas numa linguagem que impede o reconhecimento da própria parte do quanto por ela declarado.

Em concreto, não é aceitável perguntar às partes questionários mais ou menos padronizados, sem levar em conta a natureza específica do caso e sua posição específica no processo. Não creio tão pouco que se deva utilizar o mesmo tempo para se interrogar uma parte e uma testemunha. Acredito, acima de tudo, que se tratando das partes, o juiz nunca deve usar a faculdade de excluir da audiência os advogados e deve permitir-lhes que proponham, no decorrer da mesma, todas as questões que eles, melhor do que o juiz e o defensor do vínculo, devem conhecer sobre os vários detalhes do caso. Também acredito que a declaração das partes deve sempre ser coletada por um membro do colégio, reservando a assistência do auditor para o interrogatório das testemunhas. Ao mesmo tempo, é preferível sair da jurisdição para interrogar a parte, em vez de recorrer à rogatória, o que cria menos inconveniência no caso do interrogatório de testemunhas. 


\subsection{A publicação antecipada das provas}

Por último, entender a prova como uma comprovação detalhada dos fatos históricos e referir a certeza moral ao critério preferencial de um discurso comum e razoavelmente compartilhado entre as partes, dando-lhes oportunidades progressivas para pontualizar suas respectivas argumentações, requer agilizar a publicação das provas, sem esperar o decreto de publicação dos autos de que trata o c. 1598. Mesmo tratando de outro assunto, ouvi essa proposta para o Prof. Llobell em uma recente conferência. No regulamento do tribunal do Vicariato de Roma, quando deve intervir um perito, a publicação dos autos se estabelece antes da sua nomeação e da transferência da documentação.

Embora o c. 1678 permita apenas aos advogados e ao defensor do vínculo compulsar os autos antes de sua publicação, é verdade que ele confia ao juiz regulamentar a questão. Não creio que antecipar a possibilidade de ver os autos, também para as partes, contradiga claramente as normas, enquanto resulta quase obrigado para uma produção eficaz das provas. Esta proposta nada tem a ver com o segredo instrutório, uma vez que obriga apenas aos ministros do tribunal e não às partes e nem a seus defensores que, ao contrário, necessitam conhecer pontualmente os fatos da investigação. Pensar que isso facilita a corrupção das provas ou a colusão entre as partes é um preconceito gratuito; além disso, contra esse risco, a lei já prevê a possibilidade excecional de o juiz impor segredo de sumário aos distintos participantes na causa.

\section{Conclusão}

Chegando ao final desta reflexão, não é fácil formular conclusões. Penso que é mais apropriado fazer uma última consideração, esperando, com isso, evitar que toda a abordagem que propus, entendendo a prova como comprovação de fatos, tendo por critério predominante a razoável coincidência entre as partes, possa ser vista como uma abordagem de toda gratuita.

A consideração que faço tem a ver com o "habitat" processual, como um fenômeno humano portador de limites objetivos. Portanto, propor 
a prova a partir dos pressupostos da argumentação racional e progressiva entre as partes não é garantia automática para obter resultados correspondentes à verdade real. Esse pressuposto é apenas um meio para evitar que o pronunciamento de justiça na sentença seja percebido como um ato de domínio irracional.

Nada está mais longe das exigências do ordenamento canônico do que confundir a verdade e a justiça com o simples respeito de um modo de proceder, por mais racional, comunicativo e argumentativo que possa parecer, sem fazer qualquer referência aos valores subjacentes. Se assim fosse, nada impediria que as partes concordassem uma verdade processual contrária à verdade real.

O que eu quis propor hoje é que uma abordagem mais dinâmica da prova, focada na comprovação de fatos precisos e detalhados, colocando o acento na declaração de seus protagonistas, é a melhor maneira de reduzir esse risco. E embora o risco enquanto tal não desapareça, um dinamismo probatório, baseado numa comunicação exigente e construtiva entre as partes, garante pelo menos a opção de valor mais desejável que se pode esperar em relação à veracidade dos resultados, ou seja, colocando as partes em uma situação de eliminar a tentação (que todos nós sofremos, e consequentemente também eles) de considerar nossas verdades pessoais absolutas, em vez de eliminar o outro com suas próprias razões.

\section{Bibliografia}

C. Morán Bustos, El proceso "brevior" ante el Obispo Diocesano, em M. E. Olmos Ortega (ed.), Procesos De Nulidad Matrimonial. Tras la reforma del Papa Francesco, Madrid 2016.

C. PEÑA, El nuevo proceso "breviore” coram episcopo: Monitor Ecclesiasticus 130 (2015), 567-593.

C. Peña, La reforma de los procesos canónicos de nulidad matrimonial: el motu proprio "Mitis Iudex Dominus Iesus": Estudios Eclesiásticos 90 (2015), 621-682.

D. Vitali, Verso la sinodalità, Magnano, 2014. 
G. MontinI, Gli elementi pregiudiziali del processu brevior, in AA.Vv., Prassi e sfide dopo l'entrata in vigore del m.p. Mitis Iudex Dominus Iesus e del rescriptum ex audientia del 7 dicembre 2015, Città del Vaticano 2018, 62-63.

G. P. Montini, Dopo la decisione giudiziale: appello e altre impugnazioni, em REDAZIONE DI QUADERNI DI DIRITTO ECCLESIALE, La riforma dei processi matrimoniali di Papa Francesco, Milano 2016, 115.

J. Llobell, Alcune questioni comuni ai tre processi per la dichiarazione di nullità del matrimonio previsti dal m.p. "Mitis Iudex", in Seminario di studio presso la Lumsa, 30 ottobre 2015, in http://www.iuscanonicum.it/Llobell_Lumsa.pdf., 7-10.

L. SABBARESE, Nuove norme per la dichiarazione di nullitá del matrimonio, Bologna 2016.

M. Del Pozzo, Il processo matrimoniale più breve davanti al vescovo, Roma 2016.

M. J. ARroba Conde, Diritto processuale canonico, Roma ( $6^{\mathrm{a}}$ ed.) 2012.

M. J. ARroba Conde, El proceso más breve ante el Obispo, em L. RUANO - C. GUZMÁN (EDD.), Reforma de los procesos de nulidad y otras novedades legislativas de derecho canónico y eclesiástico del Estado, Madrid 2017, 249-278.

M. J. ARRoBA CONDE, La procedura extragiudiziale per la dichiarazione di nullità del matrimonio, GRUPPO ITALIANO DOCENTI DIRITTO CANONICO (ed.), Il diritto nel mistero della Chiesa, IV, Città del Vaticano 2014, 173-186.

M. J. ARRoBA CONDE, Prima analisi della riforma del processo canonico di nullità del matrimonio, in PONTIFICIA UNIVERSITÀ LATERANENSE, Convegno: Le litterae Motu proprio sulla riforma dei processi di nullità matrimoniale - una prima analisi, 13 ottobre 2015, em http://www.iuscanonicum.it/prima-analisi-sullariforma-del-processo-di-nullità. 
M. J. ARRoBA CONDE, Relación entre las pruebas y la comprobación de la verdad en el proceso canónico: Anuario de Derecho canónico 1 (2012), 11-36.

M. J. ARroba Conde, sub cc. 1671-1691, en A. Benlloch PovedA (ed.), Código de derecho canónico. Edición bilingüe, fuentes y comentarios de todos los cánones, Valencia (16 ed.) 2016, $722-738$.

M. J. ARROBA CONDE, Verità e relazione processuale nell'ordinamento canonico: sfide circa il metodo extragiudiziale, em G. DALla TORRE - C. MiRABELLI (eds.) Verità e metodo in giurisprudenza. Scritti dedicati al cardinale Agostino Vallini in occasione del 25 anniversario della consacrazione episcopale, Città del Vaticano 2014, 23-50.

M. J. ARroba Conde, La pastoral judicial y la preparación de la causa en el motu proprio Mitis Iudex Dominus Iesus, em M.E. Olmos Ortega (ed.), Procesos de nulidad matrimonial tras la reforma del Papa Francesco, Madrid 2016, 63-66).

M. J. ARRoba Conde, La recente esperienza sinodale in prospettiva canonica: Commentarium pro Religiosis et Missionariis 96 (2015), 263-286.

O. GRAZIOLI, La querela nullitatis: origini, attualità e prospettive di comparazione, Città del Vaticano 2016.

R. BURKE, La procedura amministrativa per la dichiarazione di nullità del matrimonio, em AAVv., I procedimenti speciali nel diritto canonico, Città del Vaticano 1992, 94-98. 